\title{
Experimental Characterization Methodology for the Identification of Voltage Losses of PEMFC: Applied to an Open Cathode Stack
}

\author{
A. Husar ${ }^{*}$, S. Strahl, J. Riera \\ Institut de Robòtica i Informàtica Industrial (CSIC-UPC) \\ C/ Llorens i Artigas 4-6 08028 - Barcelona (SPAIN) \\ ( $^{*}$ corresponding author: ahusar@iri.upc.edu
}

Keywords: Activation losses, Mass transport losses, Ohmic losses, PEMFC, Open cathode

\begin{abstract}
The objective of this study is to describe the methodology used to isolate the main voltage loss indicators through a simple and effective treatment of a current interrupt and current sweep. The voltage loss indicators are activation polarization, mass transport, and ohmic losses. The indicators for these losses are the Tafel slope, mass transport resistance and ohmic resistance respectively. The use of this methodology to isolate the individual voltage losses works quite well. Even though there may be some inaccuracies, the trends can be clearly seen. This methodology can be used in any PEMFC system to monitor the state of health of the fuel cell. If this method were to be automated and implemented on a periodic basis, then an on-line measurement of the individual voltage losses could be monitored. The data analysis indicates that a major objective of the controller will be to minimize the mass transport losses by implementing proper temperature control.
\end{abstract}

\section{Introduction}

Remarkable progress has been made in polymer electrolyte membrane fuel cell (PEMFC) materials, component design, production and system power density. However, there is still significant work to be done in order to understand the different physical phenomena within a working fuel cell and how they need to be controlled in order to improve efficiency, operating range and stability [Li 2008]. This experimental study is focused on identifying the major voltage losses in a PEMFC with a simple, yet effective, method using only current, voltage, and PEMFC stack temperature measurements. In the literature simple methodologies have been suggested as a way to decompose the $\mathrm{i}-\mathrm{V}$ performance curves and therefore isolate individual losses [Baghalha 2010], [Wu 2008]. The major losses to be identified are activation, mass transport and ohmic resistance. For each of these losses, indicators have been determined. The experimental methodology used to extract the individual indicators is based on two dynamic tests: current interrupt and current sweep. The extraction methods are explained and the results using these methods are presented.

First, the fuel cell voltage loss model will be explained in section 2 followed by the experimental methodology for dissecting the i-V curve in section 3. Section 4 describes the experimental setup and test conditions followed by a discussion of results and the conclusions.

The objective is to isolate and identify the main voltage loss indicators with a simple and effective treatment of a current interrupt and current sweep.

\section{Fuel Cell Voltage Losses Model}

In the widely published [O'Hayre 2009] basic fuel cell model used in this work, the fuel cell voltage $\mathrm{V}_{(\mathrm{fc})}$ is equal to the thermodynamic reversible potential $\left(\mathrm{E}_{(\mathrm{T}, \mathrm{P})}\right)$ of a 
PEM fuel cell minus the three major losses: activation $\left(\Delta \mathrm{V}_{\mathrm{act}}\right)$, mass transport $\left(\Delta \mathrm{V}_{\mathrm{mt}}\right)$ and ohmic $\left(\Delta \mathrm{V}_{\mathrm{ohm}}\right)$.

$$
\mathrm{V}_{f c}=\mathrm{E}_{(\mathrm{T}, \mathrm{P})}-\Delta \mathrm{V}_{\mathrm{act}}-\Delta \mathrm{V}_{\mathrm{mt}}-\Delta \mathrm{V}_{\mathrm{ohm}}[\mathrm{V}]
$$

The thermodynamic reversible potential is represented by the following equation [O'Hayre 2009]:

$$
E_{(T, P)}=-\left(\frac{\Delta H}{n F}-\frac{T \Delta S}{n F}\right)-\frac{R T}{n F} \ln \left(\frac{\prod a_{\text {prod }}^{v_{i}}}{\prod a_{\text {react }}^{v_{i}}}\right)
$$

where $\Delta H$ is the change in enthalpy and $\Delta S$ is the change in entropy of the reaction at standard temperature and pressure, which in this study is considered to be $25^{\circ} \mathrm{C}$ and $1 \mathrm{~atm}$ and has a value of $-285826 \mathrm{~J} / \mathrm{mol}$ and $-163 \mathrm{~J} / \mathrm{mol} / \mathrm{K}$ respectively. If more accuracy is needed then equations can be introduced to make the enthalpy and entropy a function of temperature. $n$ represents the number of electrons transferred per mole, which in this case is 2 for $H_{2}, F$ is Faraday's constant and $R$ is the universal gas constant. $\mathrm{T}$ is the fuel cell operating temperature. $\mathrm{a}_{\text {prod }}$ and $\mathrm{a}_{\text {react }}$ are the activities at the inlet conditions, which are: partial pressure of $\mathrm{H}_{2} \mathrm{O}$ vapour (the product) and $\mathrm{H}_{2}$ and $\mathrm{O}_{2}$ (the reactant) divided by the total gas pressure that enters the fuel cell. $v_{\mathrm{i}}$ is the corresponding stoichiometric coefficient of each species participating in the reaction, which is 1 for all of them except for $\mathrm{O}_{2}$, which is $v_{\mathrm{O}_{2}}=$ $1 / 2$.

\subsection{Activation polarization losses:}

A certain proportion of energy is needed to start the chemical reaction. This phenomenon produces a non-linear voltage drop called activation polarization. These losses occur on both anode and cathode catalysts. However, the oxygen reduction reaction kinetics is much slower than hydrogen oxidation reaction, and the reduction reaction produces a much larger magnitude of activation polarization loss. The oxidation reaction on the anode is much faster and practically constant through out the current range. If only a single reaction is considered then the voltage loss due to activation polarization can be described by the Tafel equation [Barbir 2005]:

$$
\Delta \mathrm{V}_{\mathrm{act}}=\frac{R T}{\alpha n F} \ln \left(\frac{i}{i_{0}}\right)=2.3 \frac{R T}{\alpha n F} \log \left(\frac{i}{i_{0}}\right)[V]
$$

The parameter $\alpha$ is the charge transfer coefficient and expresses how the change in the electrical potential across the reaction interface changes the reaction rate. It depends on the type of reaction and the electrode material. Its value is theoretically between 0 and 1 depending on the catalyst material [Larminie 2003]. It physically represents the fraction of additional energy that goes toward the cathodic reduction reaction at an electrode. The charge transfer coefficient can also be thought of as a symmetry coefficient of the electrode reaction and it is typically considered to be around 0.5 with hydrogen and oxygen reacting on a platinum catalyst [Mench 2008]. The exchange current density $i_{0}\left[\mathrm{~A} / \mathrm{cm}^{2}\right]$ is the rate at which the reaction proceeds (simultaneously in both directions) at equilibrium potential $\left(E_{(T, P)}\right)$ when the net current equals zero [Barbir 2005]. The exchange current density is a measure of the effectiveness of the electrode in promoting the electrochemical reaction where the higher the exchange current density, the lower the overall activation losses. The fuel cell current density is denoted by $i\left[A / \mathrm{cm}^{2}\right]$. The activation losses are generally the dominant effect on the fuel cell voltage, as is shown in figure 1. 
When the fuel cell is not connected to an external circuit (open circuit voltage), the fuel cell voltage would be expected to be close to the thermodynamic potential, relative to the ambient conditions and reactant partial pressure. However, the measured fuel cell voltage is much lower, usually less than $1 \mathrm{~V} /$ cell, which can be attributed to hydrogen crossover and internal currents. These losses arise because the membrane in a PEMFC is slightly electronically conductive and permeable to gasses. These losses can be considered as an internal current. The amount of current that these losses represent is rather small compared to normal operating currents. However, these internal current losses have a large effect on the voltage when the external current is very small. In this study these losses are considered part of the activation losses [Barbir 2005] and should not affect the results.

The Tafel slope is the main indicator for activation losses and will be explained in more detail in section 3.3.

\subsection{Ohmic losses:}

The resistance to the flow of electrons through the electrically conductive fuel cell components and to the flow of ions through the membrane causes a voltage drop, which can be expressed by Ohm's law:

$$
\Delta V_{\text {ohm }}=i \cdot R_{\text {ohm }}[V]
$$

The internal cell resistance $R_{\text {ohm }}$ is in $\left[\Omega-\mathrm{cm}^{2}\right]$. The electric and contact resistance can be considered constant with respect to current and temperature. Thus any change in the resistance is only dependent on membrane water concentration and membrane temperature. [Springer, 1991]

$R_{o h m}$ is the indicator for membrane ionic resistance.

\subsection{Mass transport losses:}

The consumption of reactant gases at the catalyst layers leads to concentration gradients and thus changes the partial pressure of the reactants, which affects the fuel cell voltage as seen previously in equation (2). Referring to Faraday's law of electrolysis, the transferred charge and the molar flux of a reactant $J$ are proportional to the current density [Barbir 2005]:

$$
J=\frac{i}{n F} \quad\left[m o l s^{-1} m^{-2}\right]
$$

The higher the current density, the lower the reactant concentration is at the catalyst layer.

The current density at which the reactant concentration reaches zero is called the limiting current density $\left(i_{L}\right)$. Considering this relationship between reactant mass transport and current density, the mass transport losses can be expressed as [Barbir 2005]:

$$
\Delta V_{\text {conc }}=\frac{R T}{\alpha n F} \ln \left(\frac{i_{L}}{i_{L}-i}\right)
$$

However this expression for mass transport losses does not represent the experimental values well [O'Hayre 2009]. In a forced flow open cathode fuel cell where the air reactant stoichiometry is always over 10 and the maximum current drawn from the stack is relatively low $\left(0.27 \mathrm{~A} / \mathrm{cm}^{2}\right)$ it is assumed that the mass transport losses are neglected for current densities of less than $0.04 \mathrm{~A} / \mathrm{cm}^{2}$ and are considered linear beyond that current density. High current densities are not possible with open cathode stack due to the lack of humidification and the standard operating 
conditions, hence the mass transport losses seem linear.

$$
\begin{aligned}
& \Delta \mathrm{V}_{\mathrm{mt}}=0 \text { if } i<0.04 \mathrm{~A} / \mathrm{cm}^{2} \\
& \Delta \mathrm{V}_{\mathrm{mt}}=R_{m t}(i-0.04) \text { if } \mathrm{i} \geq 0.04 \mathrm{~A} / \mathrm{cm}^{2}
\end{aligned}
$$

\section{Experimental Methodology Applied to Open Cathode PEMFC}

The following experimental approach is used to isolate the individual losses in the fuel cell stack. The data presented in the following section is an example of real data treated using this method. The main difficulty is to isolate mass transport from activation losses.

As the Nyquist plots from Electrical Impedance Spectroscopy (EIS) only give linear information at the measured point of operation, another method to determine the nonlinear losses caused by the activation are described.

Although the data used in this explanation corresponds to an open cathode fuel cell, the methodology is valid for all PEMFC.

\subsection{Current interrupt}

The purpose of the current interrupt $(\mathrm{Cl})$ is to obtain the ohmic resistance $\left(R_{\text {ohm }}\right)$ of the fuel cell in a fast and accurate manner. The principal concept is to isolate the resistance that is outside of the $\mathrm{RC}$ circuit, which should be seen as an instantaneous jump in voltage when the load is removed, because it has no capacitive component. The developed algorithm detects the jump in voltage when the load is disconnected and separates the curve in two straight lines to generate the point where the instantaneous voltage increase stops, as illustrated in figure 2 . The algorithm detects the jump by looking for 3 consecutive points of rising voltage and then uses the first point as the vertical line. Then looks for the point after the jump where the difference between the points is less than $0.002 \mathrm{~V}$ and then creates a line using the following 10 points.

EIS data has been compared to the ohmic resistance measurement via the current interrupt method in order to calibrate the detection algorithm to the EIS results, shown in figure 3.

\subsection{Current sweep}

The purpose of the current sweep is to obtain an i-V curve of the fuel cell with minimal changes to the internal conditions. This is done by quickly passing through specifically selected current set points.

In this study current sweeps were performed when the fuel cell reached steady state conditions, however it is not necessary. The time constant of the system was determined from the EIS bode diagram and is determined to be in the order of $\tau=120 \mathrm{~ms}$. It is interesting to note that the time constant of the fuel cell increases as the current decreases. The time needed for the voltage to stable out at a current set point of $0 \mathrm{~A} / \mathrm{cm}^{2}$ is much longer than at the other currents, which can be clearly seen in figure 4.

In this study the fuel cell is left at each current set point for only $300 \mathrm{~ms}$, which provided enough time for the fuel cell to stable out.

As can be seen in figure 4 there are 10 current rest points, 4 points with a difference to the operating current of $5 \%$ of the operating current and 6 points in the nonlinear region at lower current densities. The 4 points around the operating condition give a good reading of the linear slope of the fuel cell. The 6 points at the low current densities give a good reading on the nonlinear region of the fuel cell. The black line in figure 1 shows the plot of the extracted current sweep (i-V) from figure 4.

The rest time at each set point has to be kept to a minimum due to the nature of the open cathode system where the water content and the temperature in the fuel cell are driven by the current. The total time for the current sweep could be reduced 
to less than $1 \mathrm{~s}$ if necessary. However it can be noted in this test that even at a total of $3 \mathrm{~s}$, the voltage before and after the test are the same.

\subsection{Breakdown of the current sweep}

Using the resistance data from the $\mathrm{Cl}$ and assuming that mass transport losses are negligible $\left(\Delta V_{m t}=0\right)$ at current densities of less then $0.04 \mathrm{~A} / \mathrm{cm}^{2}$ (the nonlinear part of the sweep), equation (1) was solved for $\Delta V_{\text {act }}$.

$$
\Delta V_{a c t}=E_{T, P}-V_{f c}-i R_{o h m}
$$

A logarithmic function is fitted to the data from 0.00 to $0.04 \mathrm{~A} / \mathrm{cm}^{2}$ as shown in figure 5. The slope of this line in the logarithmic scale is the Tafel slope, and the intercept on the $x$ axis is the exchange current density.

$$
\text { Tafel slope }=\frac{R T}{n \alpha F}
$$

Using the fitted Tafel slope and exchange current density the line was extrapolated out to the steady state current set point. Thus the difference between the thermodynamic reversible potential $\left(E_{T, P}\right)$ and the extrapolated curve gives activation losses $\left(\Delta V_{a c t}\right)$ seen in figure 1.

Now looking back at equation (1) all the variables are known except for $\left(\Delta \mathrm{V}_{\mathrm{mt}}\right)$, which now can be solved. With this, the breakdown of the individual losses can be plotted, as shown in Figure 6.

The $x$-axis intercept of the mass transport losses are artificially set to $0.04 \mathrm{~A} / \mathrm{cm}^{2}$ due to the assumption that there are no mass transport losses at the lower current densities. This can be seen in figure 5 where the dotted trend line separates from the solid line.

Take note that the losses calculated using this method is only valid for the current and temperature at which the sweep and $\mathrm{Cl}$ were taken, which in this case is the middle point at 4 Amps and $32.2^{\circ} \mathrm{C}$.

If this method is automated and implemented on a periodic basis then an on-line measurement of the individual voltage losses could be monitored.

\section{Experimental setup \& operating conditions}

A Horizon ${ }^{\circledR} \mathrm{H}-100$ open cathode, 20 cell, $22 \mathrm{~cm}^{2}$ active area fuel cell stack in an environmental chamber was tested. The only active control mechanism employed is a single fan that both cools and provides the oxygen needed for the reaction. All the other control mechanisms are disconnected and a constant pure, dry hydrogen flow is supplied to the stack.

The ambient conditions set in the environmental chamber were $25^{\circ} \mathrm{C}$ with $90 \% \mathrm{RH}$. The steady state current densities of $0.09,0.18$, and $0.27 \mathrm{~A} / \mathrm{cm}^{2}$ correspond to 2,4 and $6 \mathrm{~A}$. The combined cathode and cooling fan was set to control a constant fuel cell temperature. The fuel cell temperature set points are: from a minimum temperature, $30,35,40,45,50,55^{\circ} \mathrm{C}$. Pure dry hydrogen was supplied to the anode at $0.36,0.71$ and 1.07 SLPM as the steady state current was increased from 2 , to 4 and $6 \mathrm{~A}$ respectively.

LabVIEW data acquisition software was used in conjunction with analog to digital converter (ADC) of the $\mathrm{NI}$ data acquisition system combined with the HCPL-788J isolation amplifier from Agilent Technologies to measure the stack voltage. The halleffect-based current sensor ACS713 from Allegro MicroSystems measures the current in the load circuit. The switch used to perform the current was an intelligent power highside switch IPS6021 from International Rectifier. Finally, the data 
acquisition card used for the high frequency test was a PCI-DAS 4020/12 from Measurement Computing, where the sampling rate can be set from $1 \mathrm{kHz}$ to $20 \mathrm{MHz}$.

\section{Results and Discussion}

In this section several results are discussed, with respect to current and ambient temperature.

The load on the stack obviously has the largest influence on the fuel cell voltage loss as seen in figure 7 . It is interesting to note that at all three currents the voltage losses decrease with an increase in temperature but it is only the $6 \mathrm{~A}$ curve that has a nonlinear decrease. The source of the nonlinearity will be discussed in section 5.2 and 5.3 and shows the practicality of this methodology as a diagnostic tool.

The next sections will discuss the evolution of the individual voltage losses at the different currents and fuel cell operating temperature.

\subsection{Activation losses evaluation}

The activation losses are shown in figure 8 . They decrease linearly with fuel cell temperature in these ranges of currents and temperatures. The reason for the linear decrease in activation losses is due to the decrease in thermodynamic reversible potential $\left(E_{0}\right)$ which decreases with fuel cell temperature, thus causing the activation losses to decrease. However, the original current sweep data does not show this decrease. The low current density current sweep data for the same current at different temperatures are identical to each other at less than $0.04 \mathrm{~A} / \mathrm{cm}^{2}$. Thus this is only a theoretical decrease in activation losses due to the order in which the data was decomposed.

The Tafel slope, being the indicator for activation losses, reflects the linearity as it seems to remain relatively constant with respect to temperature at each current tested, as shown in figure 9.

\subsection{Mass transport losses evaluation}

The mass transport losses increase greatly with the increase in current (see figure 10), which is expected according to equation 5 and 6 . All the measurement errors are incorporated into this indicator due to the order in which the voltage loss decomposition was done. However, an interesting trend is seen with regard to temperature. There is a general linear decrease in mass transport losses with the increase in fuel cell temperature and seems to be linear for temperatures lower than $50^{\circ} \mathrm{C}$. However, when temperatures go beyond $50^{\circ} \mathrm{C}$, there seems to be stabling out of the losses. This can be seen dramatically in the mass transport indicator shown in figure 11.

This elbow in the 6A data suggests that there is a change in state of the diffusion and/or catalyst layers. This could possibly be due to the evaporation of most of the liquid water in these layers allowing for maximum diffusion flux. There is a possible trade-off of maximizing diffusion with increased membrane resistance, as will be shown in the ohmic losses section.

\subsection{Ohmic resistance losses evaluation}

Ohmic losses increase with an increase in current and temperature. There seems to be a distinct upward trend as the fuel cell reaches $45^{\circ} \mathrm{C}$. This may indicate that beyond this temperature and inlet relative humidity the membrane is not fully saturated, which reinforces the hypothesis that there is no more liquid water in the layers.

Even though the ohmic losses are relatively small compared to the other losses in the fuel cell, there may be some undesirable long-term degradation caused by a dry membrane. 
The Ohmic resistance ranges from 0.115 to $0.140\left(\mathrm{Ohm}-\mathrm{cm}^{2}\right)$. This is comparable to studies in the literature which indicate ranges from 0.100 to $0.182\left(\mathrm{Ohm}-\mathrm{cm}^{2}\right)$ for Nafion 212 and 117 respectively [Hou 2011], [Büchi 1996]. Fuel cell resistance $R_{\text {ohm }}$ is relatively constant at each current for temperatures below $45^{\circ} \mathrm{C}$.

\section{Conclusions}

The proposed methodology in this work to isolate the individual voltage losses functions quite well. Even though there may be some inaccuracies, the trends are clearly seen. This methodology can be used to monitor any PEMFC state of health with respect to activation, mass transport, and ohmic losses.

It must be noted that all the power generated during the sweep would be lost. Thus it will affect the intended performance of the system. Capacitors could be placed in parallel with the fuel cell to supply the needed power during the sweep. The efficiency loss due to the sweep will be dependent on the frequency and the duration of the sweeps. This analysis has not been done but it is strongly dependent on the fuel cells design and its sensibility to the operating conditions. An optimization analysis of the sweep, in order to minimize the frequency and the duration of the sweeps, would also need to be done.

If this method is automated and implemented on a periodic base, then an on-line measurement of the individual voltage losses could be monitored.

Through analysis of the open cathode fuel cell data it is clear that a major objective of the controller will be to minimize the losses through proper control of the temperature by means of the fan.

Future work will be dedicated to determining how the hydrogen purge rate, inlet temperatures and relative humidity affect the individual losses.

\section{Acknowledgements}

All the experimental tests were performed at the Fuel Cells Laboratory of the Institut de Robótica i Informática Industrial (CSIC-UPC, Barcelona) and are only possible due to its advanced equipment and proficient technical staff. This work is partially funded by the project of CICYT DPI2010-15274 MICINN and CICYT DPI2011-25649 MICINN 


\section{References}

[Baghalha 2010] M. Baghalha, J. Stumper and M. Eikerling, Model-based deconvolution of potential losses in a PEM fuel cell, ECS Trans. 28, pg. 159-167, 2010

[Barbir 2005] F. Barbir, PEM Fuel Cells: Theory and Practice, Elsevier Academic Press, 2005

[Büchi 1996] F.N. Büchi, G. G. Scherer, In-situ resistance measurements of Nation 117 membranes in polymer electrolyte fuel cells, J. Electroanalytical Chemistry, Vol 404, pg 37-43, 1996

[Hou 2011] A study on polarization hysteresis in PEM fuel cells by galvanostatic step sweep, International Journal of Hydrogen Energy, vol 36, Is. 12, pg. 7199-7206, 2011

[Larminie 2003] J. Larminie, Fuel Cell Systems Explained 2nd Edition, John Wiley \& Sons Ltd, 2003

[Li 2008] H. Li, Y. Tang, Z. Wang, Z. Shi, S. Wu, D. Song, J. Zhang, K. Fatih, J. Zhang, H. Wang, Z. Liu, R. Abouatallah, A. Mazza, A review of water flooding issues in the proton exchange membrane fuel cell, J. Power Sources, Vol 178 pg. 103-117, 2008

[Mench 2008] M. M. Mench, Fuel Cell Engines, John Wiley \& Sons, Inc. 2008

[O'Hayre 2009] R. O'Hayre, Fuel Cell Fundamentals, John Wiley \& Sons Ltd, 2009

[Springer 1991] T. E. Springer, T. A. Zawodzinski, and S. Gottesfeld, Polymer electrolyte fuel cell model, J. Electrochem. Soc., Vol 138, No 8, 1991

[Wu 2008] J. Wu, X. Z. Yuan, H. Wang, M. Blanco, J. J. Martin, and J. Zhang, International Journal of Hydrogen Energy, Vol 33, Is. 6 1735-1746, 2008 


\section{Figure Legend}

Fig. 1. Graphical representation of equation (1) depicting the three main losses at a given current (graph based on real data $4 \mathrm{~A}$ at $32.2^{\circ} \mathrm{C}$ )

Fig. 2. Cl data for 3 tests at the same operating condition to show repeatability. Ohmic resistance using $\mathrm{Cl}$ is $0.121 \Omega-\mathrm{cm}^{2}$

Fig. 3. Nyquist plot at the same conditions (4A) as the Cl data. Ohmic resistance using EIS is $0.119 \Omega$ $\mathrm{cm}^{2}$

Fig. 4. Average cell voltage and current density dynamic of a current sweep with $300 \mathrm{~ms}$ at each point. Note that the voltage before and after the test is the same.

Fig. 5. The solid line represents the real data $\left(E_{T P}-V_{f c}-i R_{o h m}\right)$. The linear extrapolation of the lower current density points is represented by the dotted line. Note that it is in a logarithmic scale.

Fig. 6. The graph depicts the breakdown of the voltage losses from experimental data.

Fig. 7. The graph shows the evolution of total voltage loss at three different currents $2,4,6 \mathrm{~A}$ as a function of fuel cell temperature with constant environmental conditions

Fig. 8. Activation losses of the fuel cell stack

Fig. 9. Tafel slope as activation indicator

Fig. 10. Mass transport losses

Fig. 11. Linear mass transport indicator represented as a resistance for 2,4 and $6 \mathrm{~A}$.

Fig. 12. Ohmic losses with respect to current and temperature

Fig. 13. Ohmic resistance as the ohmic indicator 


\section{Figures}

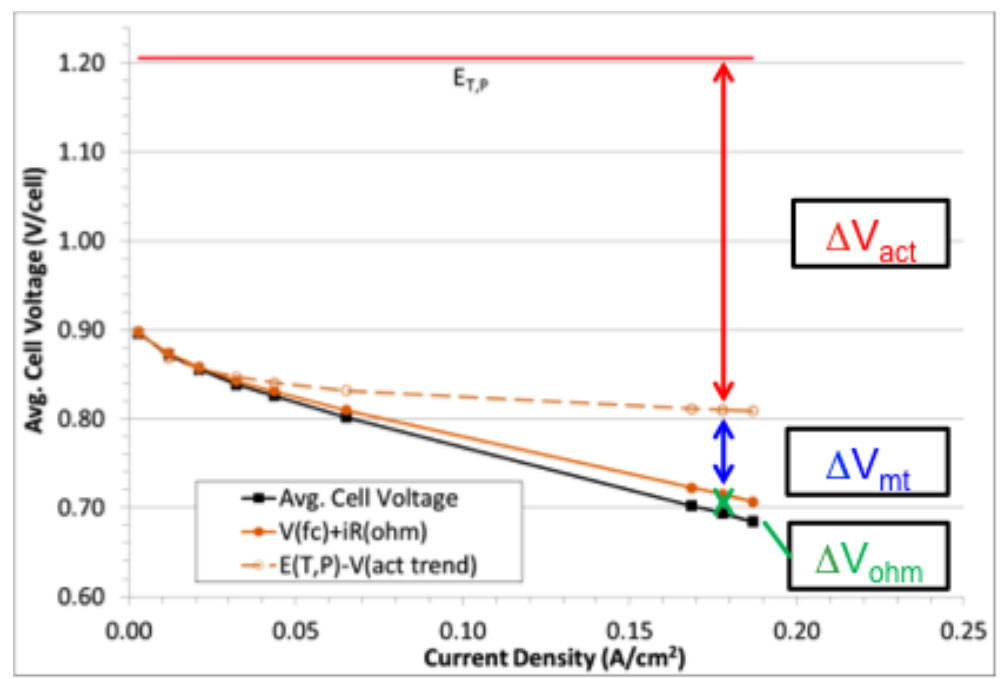

Fig. 1.



Fig. 2.

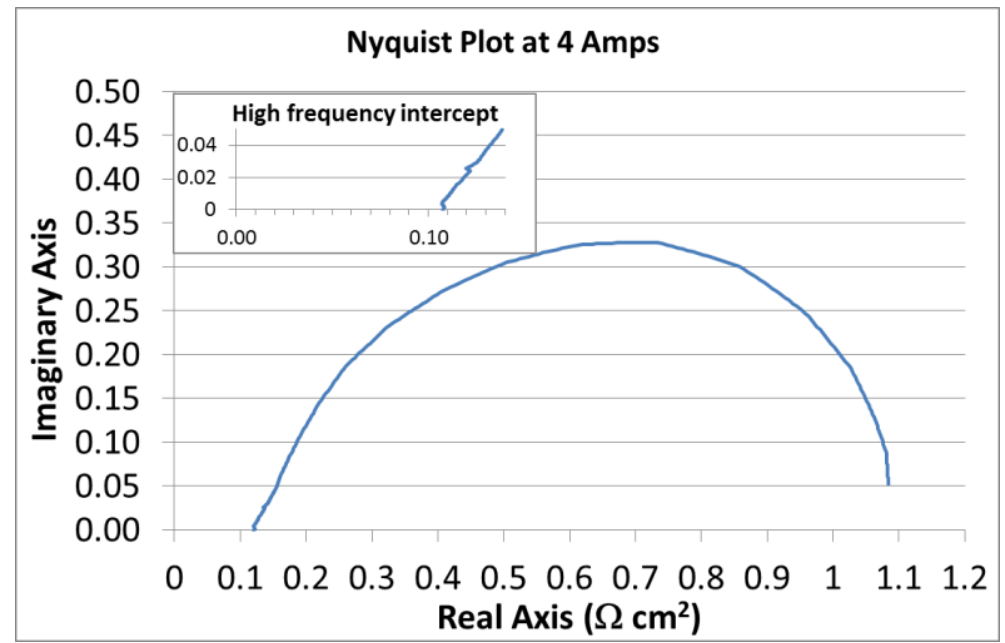

Fig. 3. 


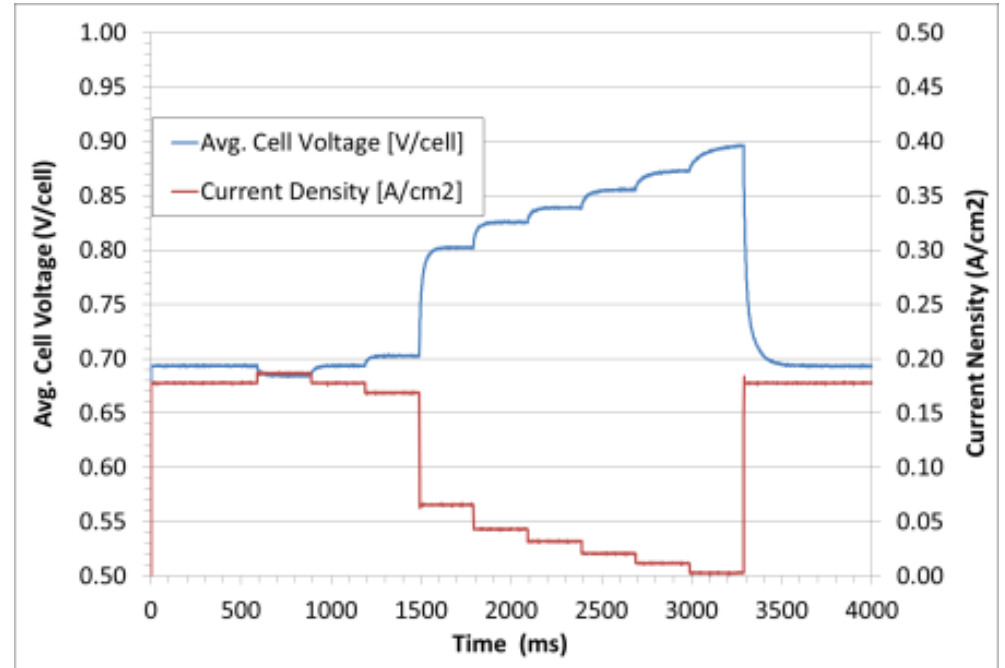

Fig. 4.

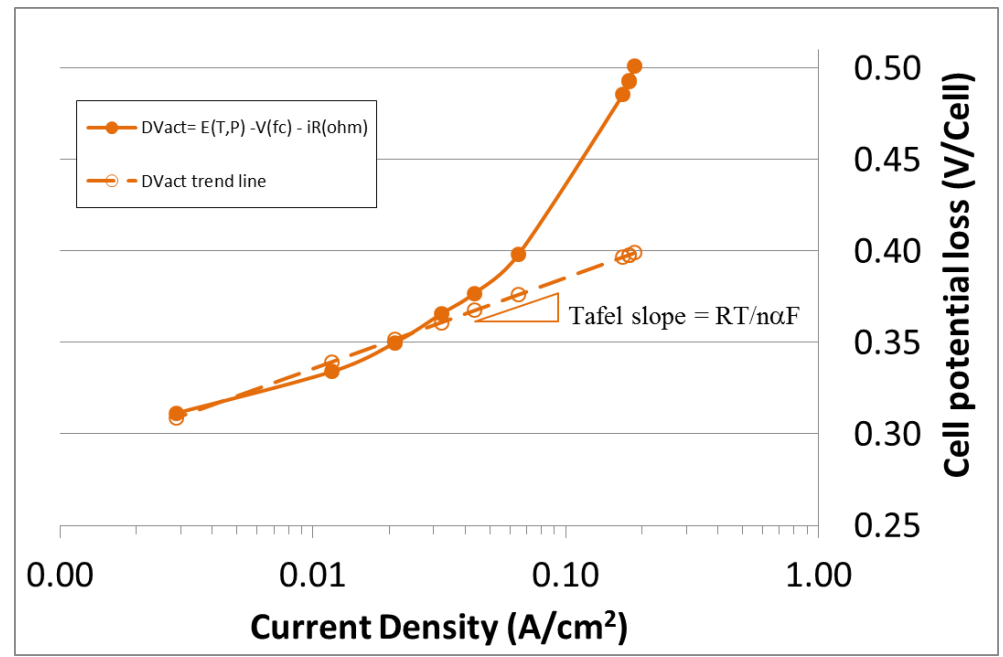

Fig. 5.

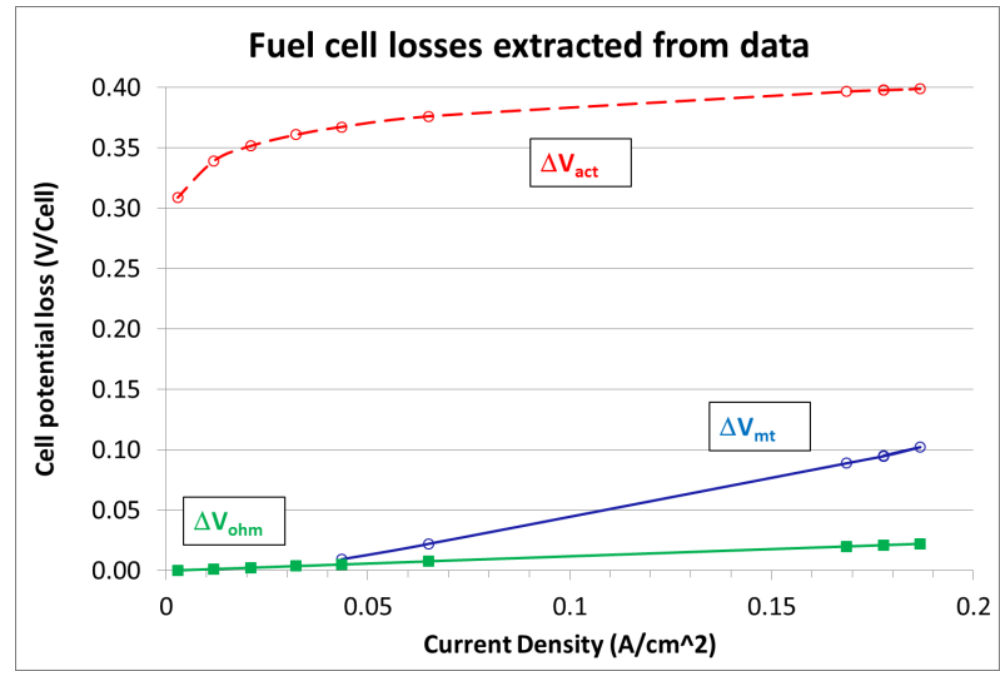

Fig. 6. 


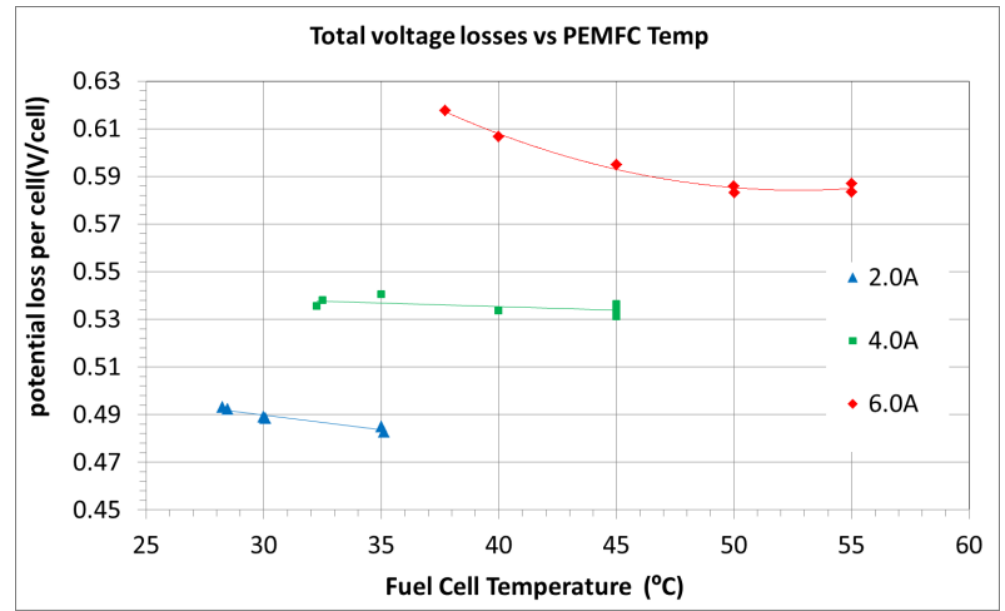

Fig. 7.

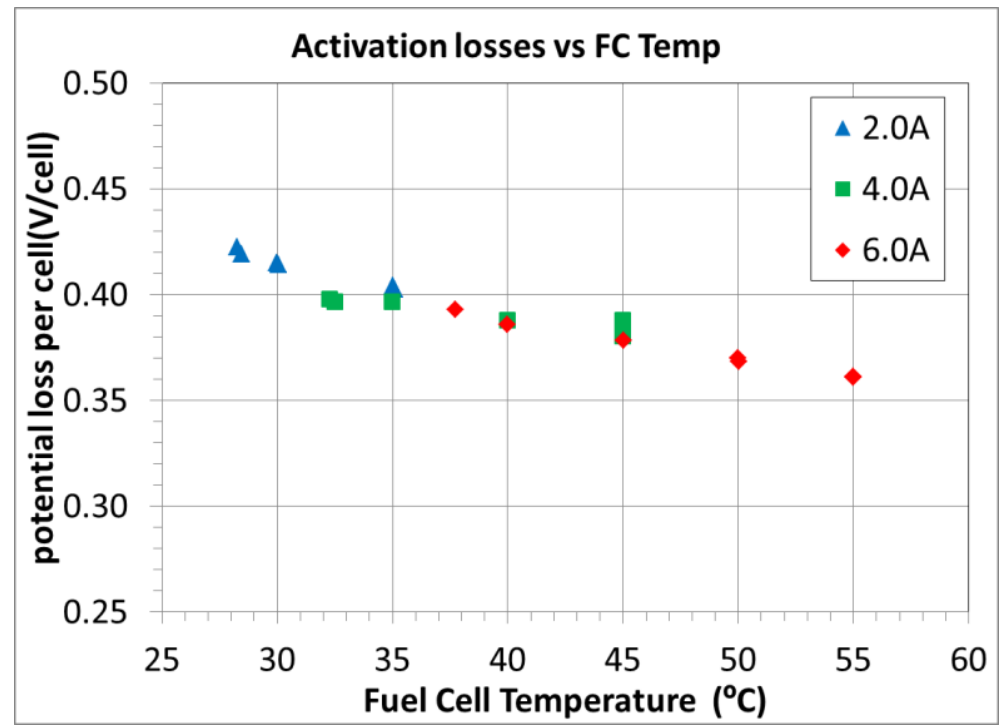

Fig. 8.



Fig. 9. 




Fig. 10.



Fig. 11.



Fig. 12. 




Fig. 13. 